\title{
Síndrome de Klippel-Trenaunay - Relato de caso
}

\author{
Klippel-Trenaunay Syndrome - Case report
}

\author{
Cristiano do Amaral de Leon ${ }^{1}$ \\ Maigrei Dani Ferrari ${ }^{3}$ \\ Bruna Jardim Maffessoni ${ }^{5}$
}

\author{
Luiz Roberto Braun Filho ${ }^{2}$ \\ Bruno Luiz Guidolin ${ }^{4}$
}

\begin{abstract}
Resumo: A síndrome de Klippel-Trenaunay é caracterizada por uma tríade composta de mancha vinho do porto, veias varicosas com ou sem malformações venosas e hipertrofia óssea e dos tecidos moles, envolvendo, geralmente, apenas uma extremidade (hipercrescimento da extremidade afetada). Sua causa continua a ser pesquisada, embora existam diversas teorias. É uma síndrome sem predileção por sexo e etnia, apresentando-se mais ao nascimento, infância ou adolescência. Apresentamos o relato de um caso de um menino de oito anos com essa síndrome.

Palavras-chave: Hipertrofia; Malformações vasculares; Mancha vinho do porto

Abstract: Klippel-Trenaunay syndrome is characterized by a triad of port-wine stain, varicose veins with or without venous malformations, and bony and soft tissue hypertrophy. It usually affects only one extremity. Its cause continues to be investigated, although theories abound. There is no predilection for gender or any particular ethnicity, and it appears more frequently at birth, childhood or adolescence. We report the case of an 8-year-old boy with this syndrome.

Keywords: Hypertrophy; Port-wine stain; Vascular malformations
\end{abstract}

\section{INTRODUÇÃO}

A síndrome de Klippel-Trenaunay (SKT) é caracterizada por uma tríade: mancha vinho do porto, varizes e hipertrofia óssea e dos tecidos moles, envolvendo, na maioria das vezes, apenas uma extremidade. ${ }^{1}$ As lesões são presentes ao nascimento e em cerca de 75\% dos pacientes manifestam-se antes dos 10 anos de idade. ${ }^{2}$ Diferencia-se da síndrome de KlippelTrenaunay-Weber (SKTW), pois nesta está presente malformação arteriovenosa da extremidade afetada. ${ }^{3}$

A origem dessa síndrome continua a ser elucidada, embora existam diversas teorias. Alguns autores acreditam que as alterações venosas desenvolvidas são consequência de uma obstrução venosa profunda ou mesmo de uma atresia das veias profundas, causando edema e hipertrofia do membro. ${ }^{4,5}$ Embora a SKT seja uma condição esporádica, trabalhos relatam casos familiares de SKT que não foram herdados de um padrão mendeliano, sugerindo uma herança multifatorial. ${ }^{6}$ Estudos realizados posteriormente por Happle sugerem que a herança de um único gene defeituoso poderia explicar o desenvolvimento dessa síndrome, bem como a ocorrência de casos esporádicos e familiares. Observou-se que as lesões são dispostas em um padrão mosaico, em que heterozigóticos de um único

\footnotetext{
Recebido em 26.02.2009.

Aprovado pelo Conselho Consultivo e aceito para publicação em 17.06.09.

* Trabalho realizado no Departamento de Internação Pediátrica do Hospital Universitário da Universidade Luterana do Brasil (Ulbra) - Canoas (RS), Brasil. Conflito de interesse: Nenhum / Conflict of interest: None Suporte financeiro: Nenhum / Financial funding: None 
gene defeituoso seriam fenotipicamente normais, porém o alelo defeituoso pode ser transmitido por muitas gerações. O traço só seria expresso quando uma mutação somática ocorre no alelo normal, na fase precoce da embriogênese, dando origem a uma população de células clonais para a mutação de SKT. ${ }^{7}$

Trata-se de uma síndrome pouco frequente em nosso meio, porém merece destaque pelo fato de que vários estudos já relatam um padrão de herança autossômica dominante em alguns indivíduos, sendo a maioria dos casos esporádicos. A teoria gênica sugere que um único gene de defeito letal em indivíduos que são homozigóticos esteja envolvido no caso.

\section{RELATO DE CASO}

M. M. E. L., oito anos, masculino, foi atendido no pronto-atendimento pediátrico do Hospital Universitário da Ulbra - Canoas (RS) - em abril de 2008, apresentando lesão vascular sangrante no pavilhão auricular esquerdo, lesões vasculares cutâneas congênitas (cutis marmorata) e hemangiomas polipoides, sendo todas as alterações no hemicorpo esquerdo. A lesão no pavilhão auricular esquerdo estava presente há duas semanas com sangramento insidioso, intercalado por períodos de melhora. Há cerca de dois anos vinha apresentando hemangiomas polipoides no hemicorpo esquerdo, sofrendo ressecções dessas lesões. Não apresentava quadro semelhante na família e não teve diagnóstico firmado em nenhum serviço em que tenha sido atendido.

Ao exame físico da admissão, apresentava-se com sinais vitais estáveis. $\mathrm{Na}$ inspeção, observaram-se lesões eritematosas de origem vascular em hemiface, região cervical e membro superior, todas as alterações do lado esquerdo, assim como presença de assimetria facial (Figura 1). Após avaliação inicial, o paciente foi internado com diagnóstico de síndrome de KlippelTrenaunay, para avaliação da cirurgia geral e genética.

Foi realizada a avaliação cirúrgica, que constatou malformação vascular hemangiomatosa na hemiface e região cervical, que apresentara sangramentos anteriores, sem sinais de infecção e/ou sangramento ativo no momento, e lesão vegetante no pavilhão auricular esquerdo com leve sangramento, que posteriormente foi cauterizada. O serviço de genética constatou assimetria da face (maior o lado esquerdo) e aparente assimetria corporal (alongamento do hemicorpo esquerdo) (Figura 2), sendo compatível com o diagnóstico de SKT.

Após o diagnóstico, solicitamos avaliação da cirurgia vascular, para pesquisar a presença de malformação arteriovenosa da extremidade esquerda, podendo assim diferenciar da síndrome de KlippelTrenaunay-Weber. Foi realizado ecodoppler arterial e venoso do MIE, sem alterações. Após completa avalia-

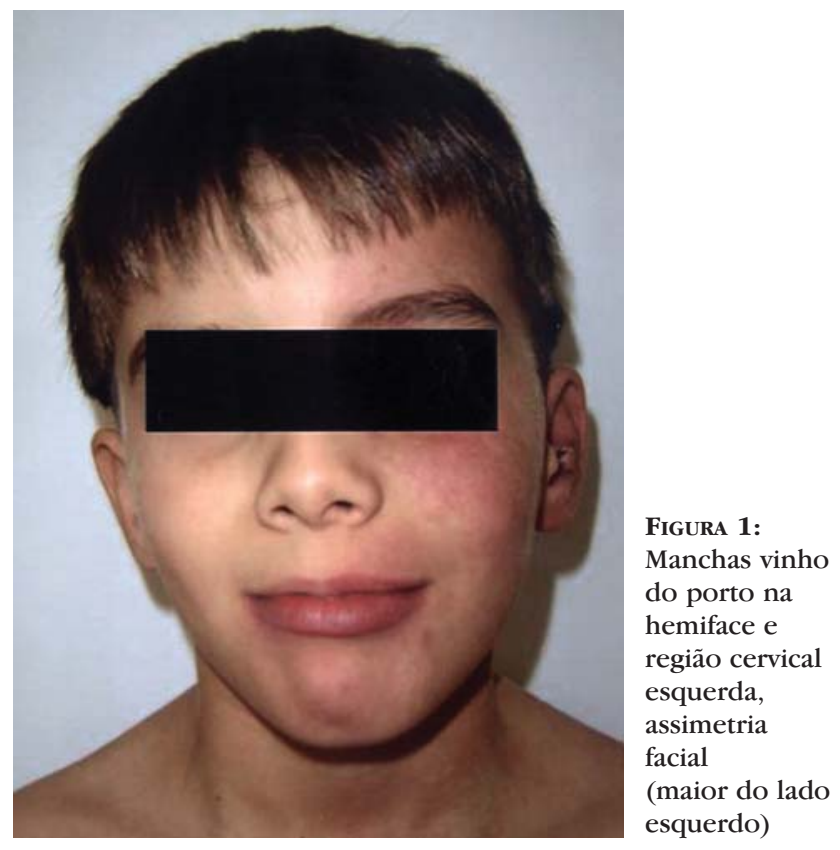

ção da cirurgia vascular e após afastarmos a suspeita de SKTW, foi solicitada avaliação da traumatologia para realizar escalonamento por megalia do membro inferior esquerdo. A equipe de neurologia também avaliou o paciente, constatando desvio de comissura labial para o lado direito, assimetria do globo ocular (maior do lado esquerdo), assimetria facial (maior do lado esquerdo) e ausência de déficit cognitivo ou hiperatividade.

No caso mencionado, o paciente recebeu alta hospitalar em boas condições clínicas e seguiu acompanhamento com dermatologista, que realizou trata-

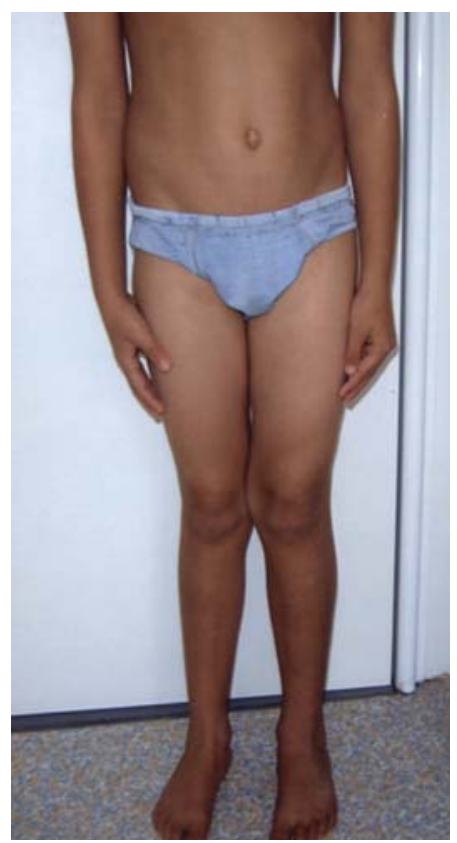

Figura 2: Assimetria corporal (alongamento do hemicorpo à esquerda) 
mento a laser das manchas vinho do porto. Segue acompanhamento com traumatologista para avaliação da discrepância entre membros inferiores, acompanhamento com a cirurgia vascular para avaliação de varizes, as quais ainda não eram visíveis ao exame físico, e acompanhamento com a equipe de genética para investigar possíveis causas.

\section{DISCUSSÃO}

A síndrome de Klippel-Trenaunay foi inicialmente descrita em 1900, como tríade que consiste de hemangiomas capilares cutâneos, hipertrofia óssea e de tecidos moles e dilatações venosas. Afeta geralmente um segmento corporal e possui gama variada de manifestações clínicas. ${ }^{8}$

A maioria dos pacientes demonstra os três sinais da síndrome clínica, sendo que o hemangioma geralmente se apresenta em primeiro lugar. ${ }^{3} \mathrm{~A}$ mancha vinho do porto ou hemangioma plano é uma malformação vascular presente ao nascimento que não apresenta tendência à involução. É frequentemente unilateral e segmentar, em geral respeita a linha média, aumenta proporcionalmente ao crescimento da criança e pode estar presente em qualquer parte do corpo, sendo a face e a região cervical os locais mais comuns. As lesões podem ser róseas na infância, mas tendem a se tornar vinhosas com a idade. ${ }^{9} \mathrm{O}$ hemangioma pode ser limitado ou estender-se a áreas mais profundas da pele, incluindo ossos, músculos e órgãos, piorando o prognóstico da síndrome.

As varizes presentes nos pacientes com a síndrome podem ser observadas na primeira infância, mas geralmente tornam-se proeminentes numa fase mais tardia, até na adolescência. ${ }^{10}$ Trata-se de uma veia grande e lateral, que inicia no pé ou na perna, proximalmente, e segue até a sua entrada na nádega ou na área do glúteo, podendo essas áreas permanecer estáveis ou aumentar gradualmente, causando dor, linfedema, tromboflebites e úlceras. ${ }^{3}$ A hipertrofia é o terceiro sinal a aparecer na síndrome e pode ser secundária a um aumento do comprimento (envolvimento ósseo) e/ou aumento da circunferência (envolvimento dos tecidos moles). Pode ser vista ao nascimento e progride durante os primeiros anos da vida. Na adolescência, quando o ciclo de crescimento da criança está concluído, o crescimento do membro irá cessar.

No caso relatado, o paciente apresentava manchas vinho do porto na face, região cervical e membro superior, todas as alterações no hemicorpo esquerdo. Os hemangiomas estavam presentes ao nascimento e com o passar do tempo escureceram, aumentando a sua superfície. As varizes ao exame físico ainda não eram visíveis, assim como no exame de imagem de membros inferiores. Era visível um leve alongamento do hemicorpo esquerdo, porém sem hipertrofia dos membros inferiores, tanto no comprimento quanto na circunferência.

A SKT deve ser suspeitada em todos os bebês com malformações capilares envolvendo uma extremidade do corpo desde o nascimento. O diagnóstico diferencial para a SKT é a síndrome de KlippelTrenaunay-Weber, síndrome de Proteus e síndrome de Maffucci, entre outras malformações capilares da pele não sindrômicas. ${ }^{10}$

Não existe nenhum tratamento curativo, e os objetivos terapêuticos são destinados a melhorar os sintomas do paciente e corrigir as consequências de lesões graves e a discrepância de comprimento. Para as manchas vinho do porto o tratamento de escolha é pulsed dye laser, sendo realizado o mais precoce possível, uma vez que as crianças mais jovens requerem um menor número de sessões e apresentam um resultado mais favorável. O resultado é melhor nas lesões localizadas na face e tronco em relação às extremidades, porém somente contribui com o tratamento superficial dos hemangiomas. ${ }^{11}$ Nas varizes, quando presentes, está indicado o uso de meias elásticas compressivas para uma melhor resposta da insuficiência venosa. O tratamento cirúrgico das varicoses é reservado para casos sintomáticos e com varizes superficiais. ${ }^{12}$ No que diz respeito à hipertrofia dos membros inferiores, o uso de aparelhos ortopédicos é uma boa opção para impedir o desenvolvimento de deformidades vertebrais. Com o tempo, a cirurgia óssea corretiva tornase necessária para tratar uma discrepância significativa no comprimentos das pernas. ${ }^{1}$

Resumidamente, os pacientes com SKT devem ser avaliados anualmente, ou mais frequente conforme a indicação clínica, mantendo a doença estável. Caso ocorra progressão da doença, exames de imagem devem ser realizados e a intervenção cirúrgica deve ser questionada para a correção da discrepância no comprimento entre os membros inferiores. Pesquisas na área de genética devem prosseguir para que futuramente possamos compreender a etiologia da doença. 


\section{REFERÊNCIAS}

1. Lane A, Darmstadt GL. Distúrbios Vasculares. In: Behrman RE, Kliegman RM, Arvin AM, Nelson: Tratado de Pediatria. Rio de Janeiro: Editora Guanabara Koogan; 1997. p. 2128-32.

2. Favorito LA. Vesical Hemangioma in patient with Klippel-Trenaunay-Weber syndrome. J Urol. 2003;29:149-50.

3. Tonsgard JH, Fasullo M, Windle ML, McGovern M, Petry PD, Buehler B. Klippel-Trenaunay-Weber Syndrome. Pediatrics: General Medicine Articles 2006. [acesso 16 Ago. 2008]. Disponível em: http://www.emedicine.com/derm/topic213.htm.

4. Servelle M. Klippel and Trénaunay's syndrome. 768 operated cases. Ann Surg. 1985;201:365-73.

5. Baskerville PA, Ackroyd JS, Browse NL. The etiology of Klippel Trenaunay syndrome. Ann Surg. 1985; 202:624-7.

6. Aelvoet GE, Jorens PG, Roelen LM. Genetic aspects of the Klippel-Trenaunay syndrome. $\mathrm{Br} \mathrm{J}$ Dermatol. 1992;126:603-7.
7. Happle R. Klippel-Trenaunay syndrome: is it a paradominant trait? Br J Dermatol. 1993; 128:465-6.

8. Kotze PG, Soares AV, Lima MC, Balidn-Junior A, Sartor MA, Bonardi RA. Síndrome de Klippel-Trenaunay: Uma causa rara de hemorragia digestiva baixa. Rev Bras Coloproct. 2002; 22:109-112.

9. Gontijo B, Pereira LB, Silva CMR. Malformações Vasculares. An Bras Dermatol. 2004;79:7-25.

10. Garzon MC, Huang JT, Enjolras O, Frieden IJ. Vascular Malformations/Part II: Associated syndromes. J Am Acad Dermatol. 2007;56:541-64.

11. Richards KA, Garden JM. The pulsed dye laser for cutaneous vascular and nonvascular lesions. Sem Cutan Med Surg. 2000;19:276-86.

12. Gloviczki P, Stanson AW, Stickler GB, Johnson CM, Toomey BJ, Meland NB, et al. Klippel Trenaunay syndrome: the risks and benefits of vascular interventions. Surgery. 1991;110:469-79.
ENDEREÇO PARA CORRESPONDÊNCIA / MAILING ADDRESS:

Maigrei Dani Ferrari

Rua Oswaldo Cruz, n. 1483 - Santa Catarina 95032400 Caxias do Sul, RS.

Tel./Fax: 51 9661-0602 543224-4655

E-mail:mai_medicina@yaboo.com.br

Como citar este artigo / How to cite this article: Leon CA, Braun Filho LR, Ferrari MD, Guidolin BL, Maffessoni BJ. Síndrome de Klippel-Trenaunay - Relato de caso. An Bras Dermatol. 2010;85(1):93-6. 